\title{
Os profissionais norte-americanos e a organização do ensino industrial brasileiro (1946-1962)
}

\author{
Ísis de Freitas CAMPOS \\ Francisca Leidiana de SOUZA ${ }^{2}$ \\ Olívia Morais de MEDEIROS NETA ${ }^{3}$
}

\begin{abstract}
Resumo
O presente estudo objetiva analisar o perfil dos profissionais norte-americanos que representaram os Estados Unidos da América, em viagens com destino ao Brasil, a fim de contribuir na organização do ensino industrial brasileiro no contexto da Comissão Brasileiro-Americana de Educação Industrial (CBAI), a qual desenvolveu as suas atividades de 1946 a 1962. Nessa perspectiva, propôs-se construir o perfil profissional desses funcionários a partir do método da prosopografia utilizando-se como fontes de pesquisa os Boletins da CBAI, órgão divulgador e informativo da Comissão. Como resultado, percebeu-se que o perfil dos funcionários que chefiaram a atuação norte-americana na CBAI era de homens com formação em ensino superior, experiência no ensino industrial e na indústria e que havia a circulação desses funcionários por diferentes países e continentes, demarcando, com isso, a presença e influência norte-americana no contexto da Guerra Fria a partir da articulação no ensino profissional.
\end{abstract}

Palavras-chave: Ensino Industrial. Estados Unidos da América. Prosopografia.

\footnotetext{
${ }^{1}$ Graduada em História pela Universidade Federal do Rio Grande do Norte e mestranda em Educação pela mesma instituição. Programa de Pós-Graduação em Educação, Universidade Federal do Rio Grande do Norte, Brasil. ORCID. https://orcid.org/0000-0003-1172-7101

E-mail: isiscampus@gmail.com

${ }^{2}$ Graduada em Pedagogia pela Universidade Potiguar e Doutoranda em Educação Profissional. Programa de PósGraduação em Educação Profissional pelo Instituto Federal de Educação, Ciência e Tecnologia do Rio Grande do Norte. ORCID. https://orcid.org/0000-0002-8037-6539

E-mail: leidy_uerntour@hotmail.com

${ }^{3}$ Doutora em Educação pela Universidade Federal do Rio Grande do Norte. Programa de Pós-Graduação em Educação, Universidade Federal do Rio Grande do Norte, Brasil. ORCID. https://orcid.org/0000-0002-4217-2914

E-mail: olivianeta@gamail.com
} 


\title{
North American professionals and the organization of Brazilian industrial education (1946-1962)
}

\author{
Ísis de Freitas CAMPOS \\ Francisca Leidiana de SOUZA \\ Olívia Morais de MEDEIROS NETA
}

\begin{abstract}
The present study aims to analyze the profile of North-American professionals who represented the United States of America in trips to Brazil, in order to contribute to the organization of Brazilian industrial education in the context of the Brazilian-American Commission of Industrial Education (CBAI), which developed its activities from 1946 to 1962. In this perspective, we proposed to build the professional profile of these employees based on the prosopography method, using as research sources the CBAI Bulletins, an organ that disseminates and informs the Commission. As a result, it was noticed that the profile of the officials who headed the North American action in CBAI constituted of men with higher education, experience in industrial teaching and industry and that there was the circulation of these officials through different countries and continents, thus demarcating the North American presence and influence in the context of the Cold War from the articulation in professional education.
\end{abstract}

Keywords: Industrial Education. United States of America. Prosopography. 


\title{
Los profesionales norteamericanos y la organización de la enseñanza industrial brasileña (1946-1962)
}

\author{
Ísis de Freitas CAMPOS \\ Francisca Leidiana de SOUZA \\ Olívia Morais de MEDEIROS NETA
}

\begin{abstract}
Resumen
El presente estudio tiene como objetivo analizar el perfil de los profesionales norteamericanos que representaron a los Estados Unidos de América en viajes a Brasil, con el fin de contribuir a la organización de la educación industrial brasileña en el contexto de la Comisión Brasileño-Americana de Educación Industrial (CBAI), que desarrolló sus actividades entre 1946 y 1962. En esta perspectiva, se propuso construir el perfil profesional de estos empleados a partir del método de la prosopografía utilizando como fuentes de investigación los Boletines del CBAI, órgano divulgador e informativo de la Comisión. Como resultado, se observó que el perfil de los funcionarios que encabezan la acción norteamericana en el CBAI, era de hombres con estudios superiores, experiencia en la enseñanza industrial y en la industria y que existía la circulación de estos funcionarios por diferentes países y continentes, marcando, así, la presencia e influencia norteamericana en el contexto de la Guerra Fría a partir de la articulación en la enseñanza profesional.
\end{abstract}

Palabras clave: Educación industrial. Los Estados Unidos de América. Prosopografia. 


\section{Introdução}

No governo de Getúlio Vargas (1930-1945), o Brasil passou a priorizar a industrialização como projeto de Governo. Na mesma direção, o setor educacional, preocupava-se com a formação de mão-de-obra especializada para executar as atividades do processo produtivo. Nessa conjuntura, o país demandava um número cada vez maior de escolas técnicas voltadas para as atividades práticas que permitissem a capacitação de trabalhadores para o desenvolvimento econômico brasileiro.

Alguns acontecimentos foram fundamentais para a possibilidade de uma mudança no setor de ensino industrial, dentre eles, podem ser mencionados: o Programa de Intercâmbio, em 1941, e a I Conferência de Ministros e Diretores de Educação das Repúblicas Americanas, em 1943, no Panamá. O primeiro, selecionava jovens nativos de países latino-americanos para estudar nos Estados Unidos da América (EUA), inclusive no setor industrial. A segunda, aprovou a Recomendação XV, intitulada de Escolas de Ensino Industrial e Técnico, a qual orientava quanto à importância de capacitar pessoas para o setor industrial. Nesse contexto, foi firmado um acordo entre o Ministério da Educação e a Fundação Interamericana de Educação que consolidava a criação de uma comissão, cuja função seria a aplicação de um programa de cooperação educacional entre o Brasil e os EUA: nascia, então, a Comissão Brasileiro-Americana de Educação Industrial (CBAI).

Criada a partir de um acordo assinado em 1946 pelo ministro da Educação Raul Leitão da Cunha e por Kenneth Holland, então presidente da agência norte-americana Office of Inter-American Affairs (OIAA), a Comissão Brasileiro-Americana de Educação Industrial (doravante CBAI) representou um instrumento para organizar o ensino industrial nacional a partir de contribuições de experiências internacionais. O acordo de cooperação entre os países foi finalizado em 1962, tendo sido renovado por algumas outras vezes ao longo desse intervalo.

A Comissão contava com a administração tanto de representantes brasileiros quanto de norteamericanos. Os representantes brasileiros foram estudados por Falcão e Cunha (2009), por exemplo. Todavia, identificou-se uma lacuna nas produções referentes à atuação da CBAI com relação ao estudo da presença dos funcionários norte-americanos que estiveram no Brasil representando seu país e sendo agentes de propagação de ideias e comunicação. Com isso, questiona-se: quem eram esses representantes? Qual(is) o(s) perfil(is) e a dinâmica de atuação desses profissionais?

Nessa perspectiva, propôs-se construir o perfil profissional desses funcionários a partir do método da prosopografia, utilizando-se como fontes de pesquisa as edições do Boletim da CBAI - 
periódico publicado pela Comissão - pesquisadas no acervo físico da Biblioteca Nacional do Brasil ${ }^{4}$ e no acervo do Departamento de Documentação Histórica da Universidade Tecnológica Federal do Paraná - UTFPR. ${ }^{5}$

Vale pontuar que este trabalho restringiu-se à identificação daqueles que ocuparam posição de codireção na direção da Comissão. No entanto, considera-se que há a possibilidade também de se estudar o perfil dos demais técnicos que estiveram em solo brasileiro no contexto desse acordo - o que pode ser objeto de estudos futuros.

\section{A Comissão Brasileiro-Americana de Educação Industrial (CBAI)}

A Comissão Brasileiro-Americana de Educação Industrial (CBAI) foi constituída, como se viu, a partir de uma articulação do Brasil com os Estados Unidos por meio da OIAA. Nos anos de 1940, houve uma intensificação na preocupação norte-americana com a política externa como resposta à ascensão da Alemanha nazista.

Nesse contexto, conforme Peres (2020), algumas agências dos Estados Unidos se empenharam na "Política de Boa Vizinhança" das relações interamericanas. Dentre elas, podemos citar a Office for Coordination of Commercial and Cultural Relations between the American Republics (OCCCRBAR) que, em 1945, recebeu o nome de Office of Inter-American Affairs (doravante OIAA). De 1940 a 1944 a agência esteve sob a direção do empresário Nelson Rockefeller e nos anos de 1945 e 1946 o posto foi ocupado por Wallace K. Harrison.

Em 1947, para dar continuidade às atividades desenvolvidas pelo OIAA, o governo dos Estados Unidos criou o Institute of Inter-American Affairs (IIAA) - uma agência que seria a fusão do OIAA com a Inter-American Educational Foundation, Inc. O órgão tinha como finalidade colaborar com os países da América principalmente nos campos da saúde pública, saneamento, agricultura e educação.

De 1942 a 1948 foram feitos acordos de cooperação em programas de educação com 14 países: Bolívia, Brasil, Chile, Costa Rica, República Dominicana, Equador, El Salvador, Guatemala, Haiti, Honduras, Nicarágua, Panamá, Paraguai e Peru. Em 1949, implementaram-se programas educacionais em sete regiões já sob a coordenação do Institute of Inter-American Affairs: Bolívia, Brasil, Equador, Guatemala, Panamá, Paraguai e Peru (PERES, 2020).

\footnotetext{
${ }^{4}$ Mais informações sobre os números pesquisados neste acervo, ver Medeiros Neta e Ciavatta (2020).

${ }^{5}$ Registramos a colaboração do pesquisador Mário Lopes Amorim para o acesso às fontes deste acervo.
} 
Neste mesmo ano, 1949, o presidente dos Estados Unidos, Harry Truman, em seu discurso de posse, ao apresentar propostas para a política externa estadunidense, sugeriu a criação de quatro diretrizes, dentre elas, cabe destacar a que ficou conhecida como Ponto IV (NOVAES, 2018). O contexto era o da Doutrina Truman, anunciada em 1947 com o objetivo de "apoiar os povos livres na resistência a tentativas de dominação por minorias armadas ou por pressões externas" (FUSER, 2005, p. 122), o que seria uma política de "contenção" do comunismo e influência soviética, evitando o "efeito dominó" (FUSER, 2005).

Sobre o Ponto IV, o Boletim da CBAI de junho de 1956 publicou:

No dia 22 deste, no Gabinete do Exmo. Sr. Ministro da Educação e Cultura, Dr. Clóvis Salgado, foi assinado, por Sua Excelência e pelo Chefe da Missão do Ponto IV para o Brasil, Sr. William E. Warne, o Têrmo Aditivo do Acordo entre os Governos do Brasil e dos Estados Unidos, para o continuado e eficiente desenvolvimento do Ensino Industrial em nosso país. (BOLETIM..., n. 6, 1956, p. 1628).

Novaes (2018), esclarece os propósitos acerca do Ponto IV:

[...] estabelecia uma verba de US\$ 45 milhões destinados aos países latinoamericanos na forma de cooperação e assistência técnica. A partir de junho de 1950, quando o Congresso dos EUA aprova o Ponto IV, a CBAI passa a se subordinar a esse programa. O Relatório do Ponto IV de 1957 estabelecia duas características básicas do Programa: a preparação de educadores e projetos para solucionar problemas educacionais que estão a entravar o progresso econômico brasileiro, e estimular o conceito de companheiros de progresso, que se enquadra tão bem dentro do conceito do sistema interamericano. (NOVAES, 2018, p. 8).

Novaes (2018) ainda acrescenta que o plano central estava pautado no levantamento e diagnóstico de como se encontrava o ensino voltado para a indústria e, para isso, contava tanto com a Divisão do Ensino Industrial - a DEI -, ligada ao Ministério de Educação e Cultura, quanto, e sobretudo, com a CBAI. A missão da CBAI se baseava então em divulgar os métodos e os procedimentos fundamentados na racionalização científica que se fizesse como um apoio na formação dos professores do ensino industrial.

O Brasil já havia recorrido à contratação de técnicos suíços e americanos, mas dessa vez estaria sendo estruturado um "verdadeiro sistema de ensino, algo sem precedentes na história da educação no Brasil”' (FALCÃO; CUNHA, 2009, p. 162). Notadamente, havia o interesse brasileiro, já que dava passos ainda iniciais na industrialização, mas também dos Estados Unidos, tendo em vista que essa cooperação representaria uma política de alianças em um contexto de disputa pela hegemonia dos norte-americanos durante a Guerra Fria. Nesse sentido, Celso Suckow da Fonseca, que foi diretor 
da Escola Técnica Nacional, registrou em História do Ensino Industrial do Brasil o "espírito de fraternidade continental” (FONSECA, 1961, p. 561) que pairava sobre essa política.

A participação dos Estados Unidos se deu tanto no trânsito de profissionais, de ideias e de equipamentos, quanto na contribuição financeira - embora o Brasil ainda representasse a maior parcela desse investimento. Nos anos iniciais de atuação da CBAI (1946-1948), os americanos contribuíram com 25\% do valor total investido no programa (CIAVATTA, 2009).

No que diz respeito às áreas de atuação da CBAI, Cunha e Falcão (2009), apresentam quatro como principais. A primeira, coordenação e difusão, refere-se aos encontros dos diretores das escolas industriais, que participavam de palestras com profissionais brasileiros e americanos. A segunda, são os cursos, os quais se referem à formação de professores do ensino industrial tanto no Brasil (cursos de férias ou itinerantes) quanto nos Estados Unidos, a partir das viagens subsidiadas pela Comissão - um investimento, inclusive, que representava, conforme Ciavatta (2009), em torno de metade do financiamento da CBAI. A terceira, as publicações, refere-se à publicação de livros e folhetins, além de um periódico mensal denominado Boletim da CBAI, órgão divulgador e informador da CBAI. E, na quarta área, os autores destacam a pedagogia e ideologia, já que houve uma disseminação dos padrões educacionais escolanovistas e do método de treinamento Training Within Industry (TWI) ou Treinamento dentro da Indústria.

O método TWI foi uma importação dos Estados Unidos que visava ao aumento da produtividade a partir da modificação na relação entre os supervisores e os trabalhadores operários (MULLER, 2012). Nesse contexto, como observa Ciavatta (2009), o aumento na produtividade não se daria pelo aumento das horas trabalhadas, mas pela intensificação do trabalho e modernização da tecnologia utilizada. Era necessário, para elevar a produtividade, um aparato para construir um trabalhador coletivo eficiente.

A sede da CBAI estava localizada no Rio de Janeiro e contava com diretores dos dois países. Um deles era o brasileiro Diretor do Ensino Industrial do Ministério da Educação e o outro o americano representante especial da agência dos Estados Unidos (a princípio Inter-American Educational Foundation, Inc. e depois Institute of Inter-American Affairs). A partir de 1957, a Comissão passou a contar com uma subsede em Curitiba, na Escola Técnica Federal do Paraná, onde funcionaria o Centro de Pesquisas e Treinamento de Professores (CPTP), que também contava com codireção. Havia ainda uma subsede em São Paulo, com a Secretaria Estadual do Trabalho (CUNHA; FALCÃO, 2009). Para Amorim (2004), 
[...] até a instalação e efetivo funcionamento do CPTP da CBAI, na Escola Técnica de Curitiba, os cursos para professores e orientadores careciam de uma melhor estruturação, muitas vezes não se realizando em determinado ano por não terem sido devidamente organizados, pela falta de uma maior divulgação, o que levou muitas vezes a serem frequentados por um número reduzido de docentes. No caso dos eventos para diretores a situação era diferente pelo fato de os mesmos serem convocados pela DEI, o que garantia boa frequência. A criação do CPTP veio no sentido de corrigir tal falha, a fim de que a CBAI pudesse cumprir seus objetivos de implementação de uma mentalidade de ensino direcionada pela Racionalização Científica, para a consecução das metas de formação de uma aristocracia do trabalho disciplinada para o incremento da produtividade, além de devidamente impregnada pelos valores do american way of life. (AMORIM, 2004, p. 244-245)

A Superintendência, destinada ao Diretor do Ensino Industrial, foi ocupada, conforme sistematizado por Cunha e Falcão (2009), pelos seguintes representantes brasileiros: Francisco Montojos (janeiro de 1947 a julho de 1949), Ítalo Bologna (julho de 1949 a março de 1951), Solón N. de S. Guimarães (março de 1951 a junho de 1953), Flávio P. Sampaio (julho de 1953 a agosto de 1955), Carlos Pasquale (interino - agosto de 1955 a dezembro de 1955), Francisco Montojos (dezembro de 1955 a fevereiro de 1961) e Arnaldo Hildebrand (fevereiro de 1961 a novembro de 1962).

No caso dos representantes dos Estados Unidos pode-se considerar a seguinte atuação, estabelecida a partir de consultas ao Boletim da CBAI, complementando informações já sistematizadas por Cunha e Falcão (2009): John Benjamin Griffing (janeiro de 1947 a fevereiro de 1947), George S. Sanders (fevereiro de 1947 a dezembro de 1947 e julho de 1948 a março de 1949), Lloyd A. Lezotte (dezembro de 1947 a julho de 1948), Edward W. Sheridan (abril de 1949 a março de 1953 e janeiro de 1955 a janeiro de 1956), Eldridge R. Plowden (abril de 1953 a dezembro de 1954), Paul C. Packer (fevereiro de 1956 a fevereiro de 1957), Thomas A. Hart (fevereiro de 1957 a abril de 1959) e Arthur F. Byrnes (maio de 1959 a novembro de 1961).

Quanto ao Centro de Treinamento, ao lado de Lauro Wilhelm, brasileiro constante em todo o período, atuaram quatro americanos em períodos distintos: Robert Stanley Hoole (setembro de 1957 a fevereiro de 1959), L. John Lipney (março de 1959 a agosto de 1959), Stanley G. Hagen (outubro de 1959 a março de 1960) e Alton D. Hill (abril de 1960 a julho de 1961). Cunha e Falcão (2009) observam que de 1961 a 1962 não houve representantes dos Estados Unidos.

$\mathrm{O}$ que se problematiza neste texto é qual era o perfil profissional dos representantes norteamericanos que vieram ao Brasil contribuir com a direção do ensino industrial brasileiro no período de atuação da CBAI. A partir dessa análise, é possível tanto entender o desenvolvimento do ensino industrial brasileiro do período quanto perceber aspectos sobre a política externa dos Estados Unidos. 


\section{A prosopografia dos diretores da CBAI}

Uma das respostas para essa questão pode ser alcançada utilizando-se o método prosopográfico (STONE, 2011). A prosopografia, como ferramenta, se remete a dois elementos basilares da história: “O primeiro refere-se às origens da ação política [...] O segundo refere-se à estrutura e à mobilidade sociais ${ }^{6}[. .] ”.($ STONE, 2011, p. 116). É pensando principalmente no segundo elemento que amparamos a pesquisa acerca dos profissionais da CBAI.

Para construir os dados, foram utilizados os Boletins da CBAI, periódico da Comissão que divulgava ideias e notícias sobre o ensino industrial, circulando nas escolas da rede, sendo o “instrumento de atuação mais contínua e de mais amplo alcance da Comissão" (FALCÃO; CUNHA, 2009, p. 164). Sobre sua publicação, considere-se que, segundo Medeiros Neta e Ciavatta (2020):

De janeiro de 1947 até novembro de 1961 foram publicados 150 números do Boletim da CBAI. Os quatro primeiros números do Boletim possuíam 12 páginas impressas em formato 210 x $297 \mathrm{~mm}$. A partir do número 4, abril de 1947, percebe-se a variação desse número para 16 páginas. Registra-se, no entanto, que em algumas edições esse número se alternou entre 15,17 ou 18 páginas, como o número 2 de novembro de 1958. (MEDEIROS NETA; CIAVATTA, 2020, p. 29).

Observou-se que o periódico apresentava biografias de profissionais em algumas edições pequenas que faziam parte da organização do ensino industrial. Além disso, ao longo de outros textos foi possível identificar aspectos sobre a atuação desses representantes no ensino industrial.

Optou-se por dividir a análise em dois grupos: o primeiro referente aos funcionários que atuaram na sede do Rio de Janeiro e o segundo relativo aos que desempenharam atividades em Curitiba. Considera-se, nesse sentido, a particularidade das experiências conforme a função de cada sede.

Pondera-se aqui que as informações encontradas já passaram por uma prévia seleção, já que foram elencados aspectos considerados relevantes para serem expostos no Boletim (é possível também que alguns dados do histórico profissional desses funcionários tenham sido omitidos propositalmente para resguardar ações da política externa). Ressalte-se que não há um padrão na elaboração desses textos, contendo algumas informações de cunho mais pessoal também, como data de nascimento ou nome de entes familiares. Por fim, considerou-se o filtro ideológico e temporal na composição desses textos, fazendo um trabalho de modificação na linguagem em alguns casos.

\footnotetext{
${ }^{6}$ Trata-se de um conjunto de problemas que envolve a análise do papel na sociedade, especialmente as mudanças nesse papel ao longo do tempo, de grupos de status específicos (usualmente da elite), possuidores de títulos, membros de associações profissionais, ocupantes de cargos, grupos ocupacionais ou classes econômicas [...] (STONE, 2011, p. 116).
} 


\section{Os norte-americanos na administração da CBAI}

\section{a) Os representantes da Inter-American Educational Foundation, Inc./Institute of Inter- American Affairs na CBAI}

Ao longo da atuação da CBAI, oito norte-americanos se revezaram no posto de representante dos Estados Unidos na direção da sede no Rio de Janeiro. A leitura dos Boletins permitiu ter dimensão do fluxo de movimentação tanto no sentido dos locais por onde esses funcionários transitavam quanto dos cargos que ocupavam.

John Griffing, por exemplo, deixou o cargo no Brasil para aceitar "uma importante posição" na American International Association, que funcionava sob a direção de Nelson Rockefeller, conforme o Boletim n 3 de 1947. Já Thomas A. Hart deixou a delegação americana no Brasil para ocupar um cargo semelhante no Haiti, que também fazia parte do programa do Ponto IV, havendo nesse país um foco no setor rural (BOLETIM..., n. 6, 1959). Nesse sentido, um mesmo funcionário poderia desempenhar funções similares em outros países não se fixando em um território.

Ademais, observou-se que nem todos os funcionários referenciados chegaram ao Brasil diretamente para ocupar a função de representante da delegação americana. Arthur F. Byrnes, por exemplo, antes de ocupar tal posto já estava em atividade no Brasil quatro anos antes, ficando no início em Belo Horizonte e por um tempo substituindo Hart no Rio de Janeiro (BOLETIM..., n. 6, 1959).

No posto de codiretores, os americanos contribuíram com a organização do ensino industrial brasileiro acompanhando de perto as instalações e participando dos encontros com os profissionais desse ramo. Realizavam, com isso, visitas e reuniões tanto no Brasil (figura 1) quanto no exterior. 
Figura 1 - Visita dos Diretores da CBAI à Escola Carboloy, da General Eletric

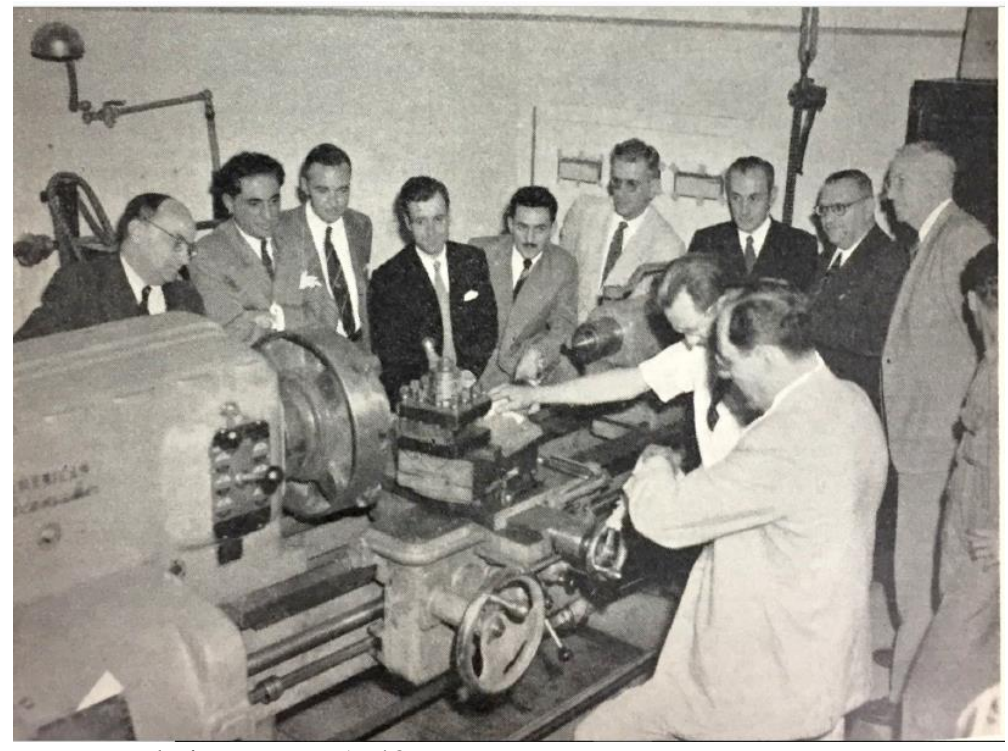

Fonte: Boletim..., n. 7, 1948.

Sobre esse último aspecto, citam-se as seis semanas em que George Sanders e Armando Hildebrand (então assistente do superintendente da CBAI) estiveram nos Estados Unidos, quando participaram da Convenção da American Vocational Association, realizada em Los Angeles, realizada anualmente e contando com "cerca de 3.000 diretores e professores do ensino industrial de todas as partes dos Estados Unidos" (BOLETIM..., n. 1, 1948, p. 16). Além disso, na ocasião, acompanharam o andamento dos cursos de treinamento dos quarenta professores brasileiros que estavam no país. Outrossim, enquanto Hildebrand voltou ao Rio de Janeiro, Sanders ainda visitou programas do Institute of Inter-American Affairs no Haiti e na República Dominicana (BOLETIM..., n. 1, 1948). Nesse sentido, os americanos podiam voltar aos Estados Unidos para processos formativos e reuniões durante o período de atuação e também acompanhar o andamento do programa em outros países.

Em relação à contribuição desses funcionários com o conteúdo dos Boletins da CBAI, notase uma baixa presença de textos. Foram encontrados, no acervo consultado, os escritos de autoria de George Sanders, "Conservação e guarda das pranchetas e instrumentos de desenho", no Boletim n. 8 de 1948, e "O problema dos grampos nas oficinas de marcenaria", no Boletim n. 9 do mesmo ano. Os dois textos apresentam instruções com relação a aspectos da oficina, portanto têm a função de disseminar conhecimento técnico.

Os quadros 1 e 2 evidenciam aspectos sobre a formação acadêmica e o histórico profissional dos norte-americanos que atuaram na chefia da sede do Rio de Janeiro. Vale pontuar que a única fonte utilizada para essa sistematização foi o Boletim da CBAI, não foi possível o acesso a todas as edições 
deste e que há uma quantidade considerável de lacunas, considerando-se que há informações sobre apenas três dos oito funcionários que estiveram no Brasil no contexto em discussão.

Quadro 1 - Dados Acadêmicos

\begin{tabular}{|l|l|}
\hline \multicolumn{1}{|c|}{ Nome } & \multicolumn{1}{c|}{ Formação } \\
\hline John G. Griffing & \multicolumn{1}{c|}{-} \\
\hline George S. Sanders & $\begin{array}{l}\text { Bacharel em Ciências e Engenheiro Mecânico pela Universidade de Agricultura e } \\
\text { Mecânica de Colorado. }\end{array}$ \\
\hline Lloyd A. Lezotte & Formou-se na Universidade de Porto Rico, em 1936. \\
\hline Edward W. Sheridan & - \\
\hline Eldridge R. Plowden & - \\
\hline Paul C. Parker & $\begin{array}{l}\text { Bacharelou-se pela Universidade de Iowa, em 1918; } \\
\text { Formou-se em Administração Escolar na Universidade de Michigan, em 1921; } \\
\text { Obteve o título de Doutor em Filosofia na Columbia University, em 1923. }\end{array}$ \\
\hline Thomas A. Hart & \\
\hline Arthur F. Byrnes & \\
\hline
\end{tabular}

Fonte: Boletins $\mathrm{n}^{\circ} 5$ de 1947, $\mathrm{n}^{\circ} 7$ de 1947, $\mathrm{n}^{\circ} 6$ de 1948, $\mathrm{n}^{\circ} 7$ de 1948, $\mathrm{n}^{\circ} 2$ de 1956.

Quadro 2 - Dados Profissionais

\begin{tabular}{|c|c|c|}
\hline Nome & Atuação na educação/ensino industrial & Outra atividade \\
\hline John G. Griffing & - & - \\
\hline $\begin{array}{l}\text { George S. } \\
\text { Sanders }\end{array}$ & $\begin{array}{l}\text { - Diretor da Escola Industrial de Arizona, em Phoenix, } \\
\text { Arizona, durante cinco anos; } \\
\text { - Diretor estadual do ensino industrial em Utah, } \\
\text { Maryland e Arizona; } \\
\text { - Fez parte do corpo de funcionários do Departamento } \\
\text { de Educação dos Estados Unidos durante alguns anos; } \\
\text { - Ministrou aulas no curso pedagógico em muitas } \\
\text { universidades nos Estados Unidos. } \\
\text { - Durante a guerra, teve a seu cargo o programa de } \\
\text { ensino técnico da Força Aérea Norte-americana, } \\
\text { treinando mecânicos de aviação, e auxiliou na } \\
\text { organização de programas de ensino nos Estados } \\
\text { Unidos e no Hawaí, Panamá e Índias Ocidentais. } \\
\text { - Chefe da Seção de Ensino Inter-American } \\
\text { Educational Foundation, inc., em Washington }\end{array}$ & $\begin{array}{l}\text { - Foi diretor do pessoal da Kelly } \\
\text { Springfield Tire Company, na fábrica } \\
\text { de Cumberland, Maryland, por muitos } \\
\text { anos. }\end{array}$ \\
\hline Lloyd A. Lezotte & $\begin{array}{l}\text { - Trabalhou na Escola de Agricultura e Artes } \\
\text { Mecânicas, no Colorado. } \\
\text { - Lecionou durante dois anos em escolas rurais de } \\
\text { Nebraska. } \\
\text { - A partir de } 1924 \text { serviu em Porto Rico como professor }\end{array}$ & $\begin{array}{l}\text { - Trabalhou durante seis anos na } \\
\text { indústria de ofícios mecânicos. } \\
\text { - Foi Secretário Executivo do } \\
\text { National War Fund durante dois anos } \\
\text { e pertenceu à Reserva de Guarda- } \\
\text { Costas da Marinha dos Estados } \\
\text { Unidos durante dois anos e meio. }\end{array}$ \\
\hline
\end{tabular}




\begin{tabular}{|c|c|c|}
\hline Nome & Atuação na educação/ensino industrial & Outra atividade \\
\hline & $\begin{array}{l}\text { de inglês, professor de escola superior, diretor de escola } \\
\text { superior, supervisor de ensino profissional e industrial, } \\
\text { organizador, supervisor e instrutor de professores em } \\
\text { ensino comercial e, finalmente, como diretor geral do } \\
\text { programa de ensino vocacional de Porto Rico. }\end{array}$ & $\begin{array}{l}\text { Serviu durante a Segunda Guerra } \\
\text { Mundial como oficial de treinamento } \\
\text { naquela corporação. Depois de ter } \\
\text { deixado este serviço como Segundo } \\
\text { Tenente, foi chamado novamente para } \\
\text { escrever a história da Legião de } \\
\text { Guarda-Costas no Décimo Distrito de } \\
\text { Guarda-Costas. }\end{array}$ \\
\hline $\begin{array}{ll}\text { Edward } & \text { W. } \\
\text { Sheridan } & \end{array}$ & - & - \\
\hline $\begin{array}{ll}\text { Eldridge } & \text { R. } \\
\text { Plowden } & \end{array}$ & - & - \\
\hline Paul C. Parker & $\begin{array}{l}\text { - Exerceu as funções de professor, supervisor e } \\
\text { administrador de escolas elementares, supervisor geral } \\
\text { de escolas públicas, diretor de universidade, Assistente } \\
\text { do Superintendente de Escolas. } \\
\text { - De } 1950 \text { a } 1953 \text { exerceu as funções de Diretor da } \\
\text { Divisão de Educação do IIAA no Paraguai e, de } 1953 \text { a } \\
\text { 1954, foi diretor da mesma divisão no Iraque. } \\
\text { - Diretor da Divisão de Educação do The Institute of } \\
\text { Inter-American Affairs, agência da International } \\
\text { Cooperation Administration. }\end{array}$ & - \\
\hline Thomas A. Hart & - & - \\
\hline Arthur F. Byrnes & - & - \\
\hline
\end{tabular}

Fonte: Boletins n. 5 (1947), n. 7 (1947), n. 6 (1948), n. 7 (1948), n. 2 (1956).

Comparando-se os perfis, observa-se que os representantes da Inter-American Educational Foundation, Inc./Institute of Inter-American Affairs na CBAI tinham vasta experiência no campo da educação profissional, além de terem pelo menos formação em ensino superior - no caso de Paul Parker, observa-se o grau de Doutor. Ademais, em dois dos casos, há especificação de atuação na indústria.

Outro ponto em comum entre os funcionários é que antes de chegarem ao Brasil estes já tinham tido experiência na organização da educação em outros países além dos Estados Unidos. Como se vê, além da presença desses funcionários na América Latina (Panamá, Índias Ocidentais, Porto Rico, Paraguai), tem-se o trânsito de Paul Parker pelo Iraque, como diretor da Divisão de Educação do IIAA, de 1953 a 1954, portanto, durante o governo de Eisenhower ${ }^{7}$. Vale lembrar que, nesse contexto, havia uma preocupação dos Estados Unidos em ocupar o controle do petróleo na

\footnotetext{
${ }^{7}$ Fuser (2005) destaca que o governo de Eisenhower deu continuidade à política externa de Truman.
} 
região do Oriente Médio, antes sob hegemonia da Grã-Bretanha (FUSER, 2005), o que explica o interesse norte-americano em desempenhar atividades na região.

\section{b) Diretores norte-americanos do Centro de Treinamento}

Pelo menos três dos profissionais norte-americanos que atuaram na chefia do Centro de Treinamento chegaram ao Brasil em 1957 com o objetivo de atuação nessa sede da CBAI, fazendo parte dos sete técnicos que compunham a equipe dos Estados Unidos no Centro em $1958^{8}$. Alton Hill chegou ao Brasil mais tarde já na situação de exercer a chefia. Na figura 2, Stanley Hoole (ao centro), primeiro diretor do Centro, aparece em uma reunião com técnicos norte-americanos, dentre os quais estavam, nas cadeiras ao seu lado, Stanley G. Hagen, técnico de Mecânica de Máquinas, e L. John Lipney, técnico de Serralharia e Tratamento Térmico de Metais, que depois assumiriam a diretoria.

Figura 2 - Técnicos norte-americanos se reúnem com o diretor Robert S. Hoole

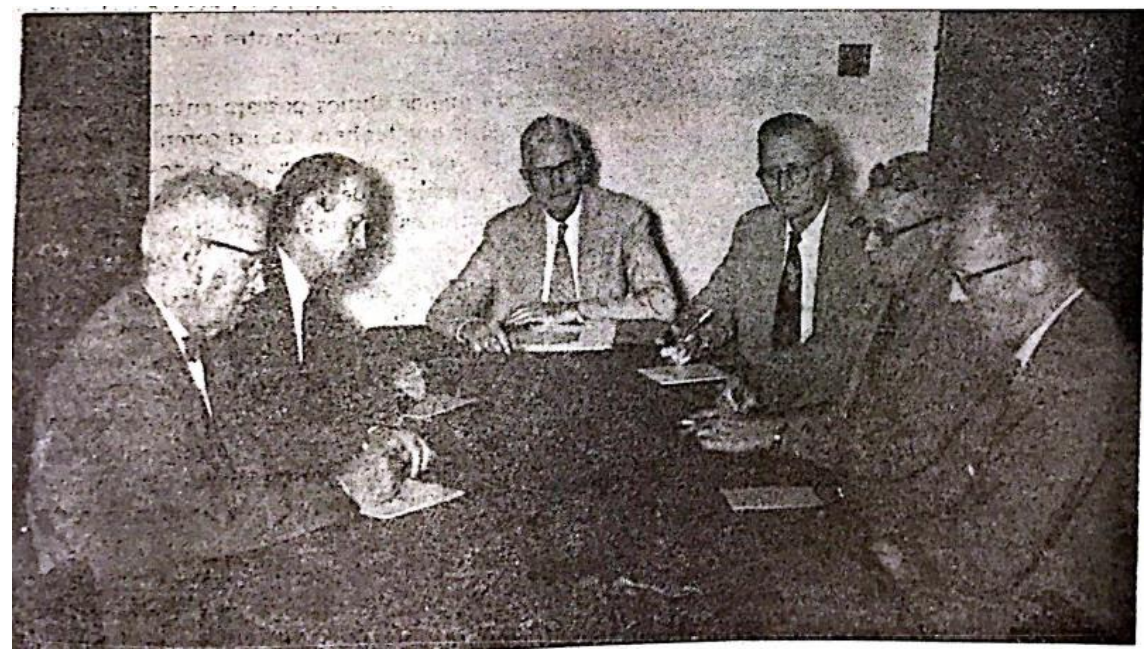

Fonte: Boletim n. 2, 1958.

O trabalho como técnico significou também a moradia no Brasil para os norte-americanos e suas famílias. Stanley Hagen, por exemplo, passou a residir com a esposa e os três filhos no bairro de Juvevê, em Curitiba (BOLETIM..., n. 2, 1959). Com isso, os funcionários passaram a compor também a vida social da cidade. Registrou-se no Boletim da CBAI (1960), inclusive, a movimentação com a viagem de Hagen aos Estados Unidos (figura 3) após dois anos de atuação no Brasil, evidenciando a socialização do funcionário:

Os dias que antecederam ao seu embarque foram cheios para o casal Hagen, já que tanto o Sr. Hagen como D. Mildred são estimadíssimos em Curitiba, contando com

\footnotetext{
${ }^{8}$ Robert S. Hoole - Diretor Técnico; Edwin W. Doe - Técnico de Fundição; Louis J. Drake - Técnico de Marcenaria; Stanley G. Hagen - Técnico de Mecânica de Máquinas; L. John Lipney - Técnico de Serralharia e Tratamento Térmico dos Metais; Kjartan Turmo - Técnico de Rádio e Eletricidade; Robert S. Goulet - Técnico de Mecânica de Automóveis. (BOLETIM..., n. 2, 1948).
} 
muitos amigos que queriam, de algum modo, expressar-lhes amizade, oferecendo ao casal coquetéis e jantares.

Os professores da CBAI também se juntaram a esse número de admiradores e lhes ofereceram um almoço no Pinheirinho, aprazível lugar dos arredores de Curitiba. (BOLETIM..., n. 2, 1960, p. 2).

Sobre isso, pode-se citar ainda a edição de abril de 1958 do Diário do Paraná (Órgão dos Diários Associados) a qual noticiou, na seção sobre a semana do "society curitibano", o "elegante cocktail" promovido por Stanley Hoole e sua esposa em sua residência. (DIÁRIO..., 1958, p. 11).

Figura 3 - Stanley Hagen e sua esposa partindo para os Estados Unidos

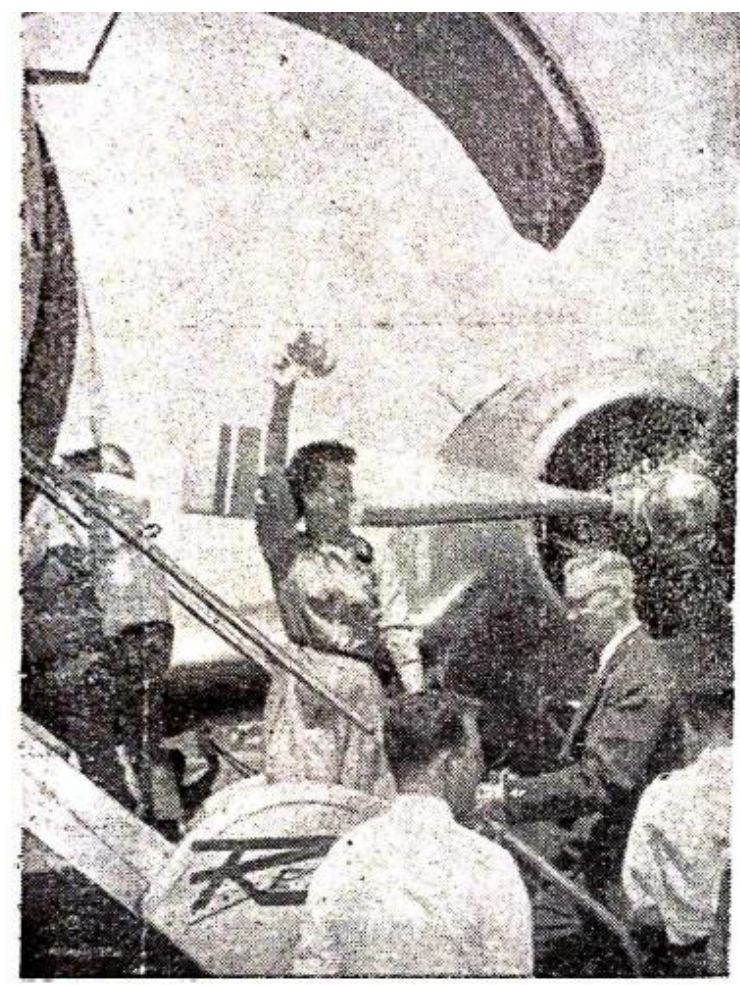

O Sr. Hagen e sua senhora quando subiam a escada do avião que os levou aos Estados Unidos.

Fonte: Boletim n. 2, 1960

Quanto à atuação como diretores, além de contribuírem com a estruturação das atividades desenvolvidas pela CBAI, esses funcionários também participavam diretamente da realização dos eventos e cursos promovidos pela Comissão, como os encontros para formação de diretores, conforme observa-se na figura 4. 
Figura 4 - Robert Hoole pronunciando um discurso no Seminário de Diretores

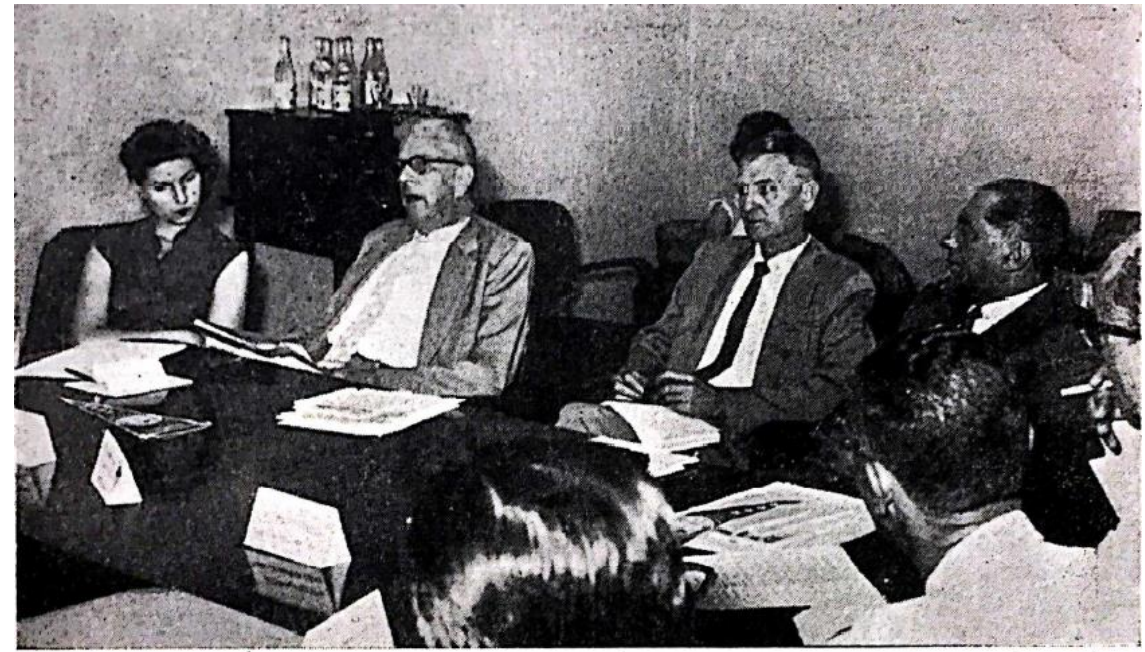

Fonte: Boletim n. 2 (1959).

Além disso, constou entre suas funções a realização de missões a outros países para observar como estava se desenvolvendo o ensino industrial e pensar possíveis conexões com as escolas brasileiras. O Boletim n. 3 de 1959 expôs uma visita a escolas argentinas realizada por Robert S. Hoole em outubro de 1958, quando era diretor do Centro de Treinamento. Após os dias que passou na região, o diretor produziu um relatório, publicado no Boletim, com observações sobre o que estava sendo desenvolvido no país e sugeriu um intercâmbio entre funcionários do ensino industrial brasileiro e argentino.

Para realizar essas atividades, era necessário que os representantes apresentassem experiência e um currículo que legitimasse essas posições. O perfil acadêmico e profissional desses norteamericanos pode ser observado nos quadros 3 e 4 . Saliente-se que, diferente do grupo anterior, conseguiu-se, neste caso, informações sobre todos os funcionários que estiveram na direção do Centro.

Quadro 3 - Dados Acadêmicos

\begin{tabular}{|l|l|}
\hline \multicolumn{1}{|c|}{ Nome } & \multicolumn{1}{c|}{ Formação } \\
\hline $\begin{array}{l}\text { Robert S. } \\
\text { Hoole }\end{array}$ & Bacharel em Ciências, Universidade de Buffalo, Nova York. \\
\hline $\begin{array}{l}\text { L. John } \\
\text { Lipney }\end{array}$ & $\begin{array}{l}\text { Bacharel em Ciências da Educação Industrial e Profissional, Universidade Estadual de Oklahoma, } \\
\text { Stillwater; } \\
\text { Recebeu o diploma de professor e habilitação para administração escolar, Universidade de Oregon; } \\
\text { Fez ainda os seguintes cursos: Tratamento Térmico de Metais e Metalografia - Universidade de Illinois, } \\
\text { Solda Elétrica Especial de Engenharia - Politécnica John Huntington, Solda de Aviação e Serralharia - } \\
\text { Escola Técnica de Aviação "Chanute Field" Rantoul, Cursos de Transição de Aviões B-25, B-17, B-29 } \\
\text { e B-47 na fábrica de aviação militar. }\end{array}$ \\
\hline
\end{tabular}




\begin{tabular}{|l|l|}
\hline $\begin{array}{l}\text { Stanley G. } \\
\text { Hagen }\end{array}$ & $\begin{array}{l}\text { Bacharel em Ciências da Educação Industrial (1939), Faculdade de Wisconsin; } \\
\text { Fez um estágio de dois anos como instrutor na oficina de mecânica em Sheboygas, Wisconsin. }\end{array}$ \\
\hline $\begin{array}{l}\text { Alton } \\
\text { Hill D. }\end{array}$ & $\begin{array}{l}\text { Bacharel em Artes e Mestre em Ciências, Universidade de Minnesota; } \\
\begin{array}{l}\text { Fez cursos de verão no Colégio Estadual de Pensilvânia e vários cursos breves sobre liderança e } \\
\text { supervisão na indústria. }\end{array}\end{array}$ \\
\hline
\end{tabular}

Fonte: Boletins n. 2 (1958), n. 3 (1958), n. 2 (1959), n. 1 (1960).

Quadro 4 - Dados Profissionais

\begin{tabular}{|c|c|c|}
\hline Nome & Atuação na educação / ensino industrial & Outra atividade \\
\hline $\begin{array}{l}\text { Robert S. } \\
\text { Hoole }\end{array}$ & $\begin{array}{l}\text { - Sêneca Vocational High School (professor, chefe de departamento, } \\
\text { assistente de diretor); } \\
\text { - McKinley Vocational High School (diretor); } \\
\text { - Durante a } 2^{\circ} \text { Guerra Mundial, atuou no treinamento para indústrias } \\
\text { bélicas; } \\
\text { - Supervisionou o programa estadual "Currículo e laboratório" (1948- } \\
\text { 1953) de preparação de material didático. } \\
\text { - Participou de um conselho para organização do ensino industrial de } \\
\text { Taiwan (1953 a 1957). }\end{array}$ & $\begin{array}{l}\text { Serviu ao exército na } 1^{\text {a }} \text { Guerra } \\
\text { Mundial (dois anos). }\end{array}$ \\
\hline $\begin{array}{l}\text { L. John } \\
\text { Lipney }\end{array}$ & $\begin{array}{l}\text { - Escola Aeronáutica Spartan de Tulsa-Oklahoma (instrutor e } \\
\text { supervisor de oficinas); } \\
\text { - Diretor de um programa de treinamento de mecânicos na força } \\
\text { aérea; } \\
\text { - Assistente de supervisor de educação vocacional e da educação de } \\
\text { adultos do sistema escolar público de Portland, Oregon. }\end{array}$ & $\begin{array}{l}\text { Serviu no departamento de } \\
\text { engenharia do exército e na } \\
\text { força aérea durante oito anos; } \\
\text { Sócio da Phi Delta Kappa. }\end{array}$ \\
\hline $\begin{array}{l}\text { Stanley G. } \\
\text { Hagen }\end{array}$ & $\begin{array}{l}\text { - Atuou como instrutor de oficina mecânica em Richmond, Califórnia } \\
\text { (1949-1957). }\end{array}$ & $\begin{array}{l}\text { Serviu durante a } 2^{\mathrm{a}} \text { Guerra } \\
\text { Mundial à marinha como } \\
\text { oficial; } \\
\text { Atuou como ferramenteiro. }\end{array}$ \\
\hline $\begin{array}{l}\text { Alton D. } \\
\text { Hill }\end{array}$ & $\begin{array}{l}\text { - Atuou por onze anos como professor de matérias industriais em } \\
\text { escolas secundárias; } \\
\text { - Dois anos como coordenador de Educação Vocacional em escolas } \\
\text { secundárias; } \\
\text { - Um ano como Assistente Estadual de Supervisor em educação } \\
\text { profissional do Estado de Minnesota; } \\
\text { - Cinco anos como professor de Educação Industrial da Universidade } \\
\text { de Minnesota; } \\
\text { - Seis anos como especialista em Educação Vocacional para o } \\
\text { governo dos Estados Unidos na Alemanha; } \\
\text { - Sete anos como Diretor de Educação Vocacional e Educação de } \\
\text { Adultos, em Racine, no Estado de Wisconsin. }\end{array}$ & - \\
\hline
\end{tabular}

Fonte: Boletins n. 2 (1958), n. 3 (1958), n. 2 (1959), n. 1 (1960).

A análise dos quadros 3 e 4 evidencia que todos os funcionários norte-americanos que ocuparam a chefia do Centro de Treinamento da CBAI contavam com formação em ensino superior em diferentes instituições. Destaque-se a existência do curso de Ciência da Educação Industrial em faculdades dos Estados Unidos. Outrossim, alguns deles fizeram cursos técnicos relacionados à indústria e inclusive tinham experiência prática. 
Quanto à atuação profissional na área do ensino industrial, nota-se uma diversidade de currículo. Percebe-se também que os dois mais experientes profissionais (Robert S. Hoole e Alton D. Hill) integraram a equipe já na posição de chefia (como já dito, Alton D. Hill chegou ao Brasil depois dos outros), enquanto Stanley Hagen, que apresenta a menor experiência na área, assumiu o posto depois de um período atuando enquanto técnico no Centro.

Outro ponto que pode ser destacado é a presença de dois funcionários que tiveram atuação anterior no ensino industrial em outros países. Observou-se uma missão de Hoole a Taiwan (função que exercia antes de viajar ao Brasil), a qual contou com o apoio do governo dos Estados Unidos e de Hill à Alemanha.

A viagem de Robert Hoole, resultado de um contrato entre a Universidade Estadual da Pensilvânia e a Universidade de professores de Taiwan com apoio do governo dos Estados Unidos, está inserida no contexto da política externa norte-americana na região na década de 1950. O governo do Kuomintang ${ }^{9}$ da ilha era legitimado pelo Ocidente na ocasião da Guerra Fria e a região recebeu apoio financeiro dos Estados Unidos, contribuindo para a industrialização - política desenvolvida para o crescimento econômico (ALBUQUERQUE, 2017).

Com relação à Alemanha, sabe-se que a região sofreu intensos bombardeios dos aliados durante a Segunda Guerra, muitos destinados à destruição de seu parque industrial. A sua recuperação está associada ao Plano de Recuperação Europeia (Plano Marshall), anunciado por Truman em 1948, o qual visava a uma integração entre os países da Europa, promovendo estabilidade e dificultando a intervenção da União das Repúblicas Socialistas Sovieticas - URSS (MASSIERE; LIMA, 2018). Fazendo-se o cálculo a partir dos dados obtidos, percebe-se que o período no qual Alton Hill esteve na Alemanha antecede o pronunciamento do Plano, demonstrando elementos anteriores da política americana no país ligadas à assistência no ensino profissional.

\section{Considerações finais}

A análise feita evidenciou que o perfil dos funcionários que chefiaram a atuação norteamericana na CBAI, tanto na sede do Rio de Janeiro quanto na de Curitiba, era de homens com experiência, em geral, no ensino industrial e na indústria, além da formação em ensino superior.

\footnotetext{
${ }^{9}$ É preciso lembrar que, depois de 1949, com a proclamação da República Popular da China por Mao Tse Tung na parte continental, Chiang Kai-shek e seus seguidores, do Kuomintang - KMT (partido nacionalista), refugiaram-se na ilha de Taiwan, de onde passaram a governar reinvidicando soberania sobre toda a China (ALBUQUERQUE, 2017).
} 
Uma outra característica observada foi a circulação desses funcionários, transitando por diferentes países e continentes, demarcando, com isso, a presença e influência norte-americana no contexto da Guerra Fria a partir da articulação no ensino profissional.

Ainda é importante registrar que, nesta análise inicial, como se viu, não se obteve o histórico profissional de todos os agentes, havendo lacunas com relação ao primeiro grupo. Com isso, evidencia-se que há espaço de pesquisa para os que se interessarem pela investigação. $\mathrm{O}$ trabalho nessa perspectiva pode inclusive explorar novos tipos de documentos, os quais possam dar mais detalhes sobre o tipo de atuação desenvolvida por esses funcionários em território nacional e também em outras regiões.

\section{Referências}

AMORIM, M. L. Da Escola Técnica de Curitiba à Escola Técnica Federal do Paraná: projeto de formação de uma aristocracia do trabalho (1942-1963). 2004. Tese (Doutorado em Educação) Programa de Pós-Graduação em Educação, Faculdade de Educação da Universidade de São Paulo: São Paulo.

ALBUQUERQUE, A. B. Coreia do Sul e Taiwan: Uma história comparada do pós-guerra. In: XII Congresso Brasileiro de História Econômica \& $13^{\mathrm{a}}$ Conferência Internacional de História de Empresas, 2017, Niterói. Anais..., Niterói, 2017. p. 28-30. Disponível em: http://www.abphe.org.br/uploads/ABPHE\%202017/7\%20Coreia\%20do\%20Sul \%20e\%20Taiwan.pdf. Acesso em: 15 jul. 2021.

BOLETIM DA CBAI. Curitiba: Comissão Brasileiro-Americana de Educação Industrial, 1958-1961. n. 1,1960 .

BOLETIM DA CBAI. Curitiba: Comissão Brasileiro-Americana de Educação Industrial, 1958-1961. n. 2, 1960 .

BOLETIM DA CBAI. Curitiba: Comissão Brasileiro-Americana de Educação Industrial, 1958-1961. n. 2, 1958.

BOLETIM DA CBAI. Curitiba: Comissão Brasileiro-Americana de Educação Industrial, 1958-1961. n. 2, 1959 .

BOLETIM DA CBAI. Curitiba: Comissão Brasileiro-Americana de Educação Industrial, 1958-1961. n. 3, 1958 .

BOLETIM DA CBAI. Curitiba: Comissão Brasileiro-Americana de Educação Industrial, 1958-1961. n. 6,1959 .

BOLETIM DA CBAI. Rio de Janeiro: Comissão Brasileiro-Americana de Educação Industrial, 19471957, n. 2, 1956. 
BOLETIM DA CBAI. Rio de Janeiro: Comissão Brasileiro-Americana de Educação Industrial, 19471957, n. 3, 1947.

BOLETIM DA CBAI. Rio de Janeiro: Comissão Brasileiro-Americana de Educação Industrial, 19471957, n. 5, 1947.

BOLETIM, DA CBAI. Rio de Janeiro: Comissão Brasileiro-Americana de Educação Industrial, 1947-1957, n, 1, 1948.

BOLETIM DA CBAI. Rio de Janeiro: Comissão Brasileiro-Americana de Educação Industrial, 19471957, n. 6, 1948.

BOLETIM DA CBAI. Rio de Janeiro: Comissão Brasileiro-Americana de Educação Industrial, 19471957, n. 7, 1947.

BOLETIM DA CBAI. Rio de Janeiro: Comissão Brasileiro-Americana de Educação Industrial, 19471957, n. 7, 1948.

CIAVATTA, M. Mediações históricas de trabalho e educação: gênese e disputas na formação dos trabalhadores. Rio de Janeiro: Lamparina, 2009, p. 1930-60.

DIÁRIO DO PARANÁ. Curitiba, 25 abr. 1958, p. 11. Disponível em: http://memoria.bn.br/DocReader/DocReader.aspx?bib=761672\&Pesq=Hoole\&pagfis=21159.

Acesso em: 20 jul. 2021.

FALCÃO, L. Q; CUNHA, L. A. Ideologia, política e educação: a CBAI (1946/1962). Revista Contemporânea de Educação, v. 4, n. 7, p. 149-176, 2009.

FONSECA, C. S. História do ensino industrial no Brasil. 1º. Vol. Rio de Janeiro, RJ: ETN, 1961. FUSER, I. O petróleo e o envolvimento militar dos Estados Unidos no Golfo Pérsico (1945-2003). Dissertação de mestrado em Relações Internacionais, apresentada ao Programa de Pós-Graduação em Relações Internacionais “Santiago Dantas”, da Unesp, Unicamp e PUC-SP, São Paulo, 2005.

MASSIERE, M. A.; LIMA, C. M. Dos escombros à liderança: A reconstrução alemã no pós-guerra e suas bases econômicas para as décadas seguintes. Revista Neiba: Cadernos Argentina-Brasil, v. 7, n. 1, p. 1-10, 2018.

MEDEIROS NETA, O. M.; CIAVATTA, Maria. Fontes para a história da educação profissional: boletim da CBAI [recurso eletrônico]. João Pessoa: Ideia, 2020.

MUELLER, R. R. A Relação Histórica Entre Trabalho e Educação: O Caso do Training Within Industry (TWI) e a Reestruturação Produtiva. Diálogos-Revista do Departamento de História e do Programa de Pós-Graduação em História, v. 16, n. 1, p. 257-280, 2012.

NOVAES, B. W. D. O ensino da matemática nas Escolas Técnicas Federais: a influência da CBAI (Comissão Brasileiro-Americana de Ensino Industrial) na formação docente. In: ENCONTRO NACIONAL DE PESQUISA EM HISTÓRIA DA EDUCAÇÃO MATEMÁTICA, 2018, Campo Grande, Anais..., 2028. Disponível em: https://periodicos.ufms.br/index.php/ENAPHEM/article/ view/7942/5662. Acesso em: 23 jul. 2021. 
PERES, E. A série de livros de leitura para a América Latina no contexto da política do Institute of Inter-american Affairs (USA). Revista de História da Educação, v. 24, n. e93692, p. 1-32, 2020. Disponível: file:///C:/Users/leidy/Downloads/93692-408011-1-PB.pdf. Acesso em: 11 jul. 2021.

STONE, L. Prosopografia. Revista de Sociologia Política, v. 19, n. 39, p. 115-137, 2011. Disponível em: https://revistas.ufpr.br/rsp/article/view/31689. Acesso em: 13 jul. 2021.

Recebido em: 21/09/2021

Aprovado em: 21/10/2021 